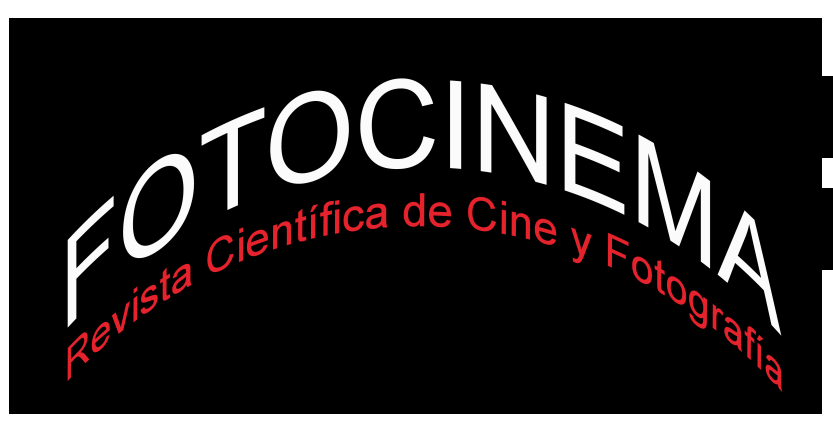

\title{
LA HISTORIA DE LA FOTOGRAFÍA ANTE UN NUEVO TIEMPO CULTURAL: REFLEXIONES PARA UN ENCUENTRO INTERDISCIPLINAR
}

\section{THE HISTORY OF PHOTOGRAPHY AND A NEW CULTURAL TIME: SOME REFLECTIONS FOR AN INTERDISCIPLINARY MEETING}

\section{Resumen:}

La fotografía, en tanto que fenómeno cultural y objeto de estudio por la Historia y las Ciencias Sociales, está también afectada por los intensos cambios que la digitalidad ha producido y que afectan tanto a su estructura tecnológica como a su propia identidad social y cultural.

Desde los inicios de la imagen digital se ha hablado de una supuesta "muerte" de la Fotografía y la aparición de una nueva tipología de imágenes que han quebrado la línea histórica que identificaba a la Fotografía en su evolución en los siglos XIX y XX.

$\mathrm{El}$ artículo analiza éstas cuestiones con algunas de las reflexiones que se produjeron desde la década de los años noventa y reflexiona sobre las estrategias en las que debería moverse una historia de la fotografía que no ignore algunos de los postulados de la posmodernidad y al mismo tiempo se enfoque en un análisis "transversal" del fenómeno cultural, social y tecnológico de la Fotografía.

\author{
Bernardo Riego Amézaga \\ Universidad de Cantabría, España \\ briego@unican.es
}

\begin{abstract}
:
The Photography as a cultural phenomenon object of study the History and Social Sciences, is also affected by the intensive changes that occurred by the digitaly process and affecting both its technological structure and its own social and cultural identity.

Since the beginning of the digital image has been talked about a supposed "death" of Photography and the emergence of a new typology of images that have broken the story line that identified Photography in its evolution in the nineteenth and twentieth centuries.

The article discusses these issues with some of the thoughts that occurred since the early nineties and reflects on the strategies that should move a history of photography that does not ignore some of the postulates of postmodernism and at the same time approach to a "transversal" analysis of the cultural, social and technological phenomenon of Photography.
\end{abstract}

\section{Palabras clave:}

Historia de la fotografía; posmodernidad y relato histórico; historiografía fotográfica; fotografía y cultura digital.

\section{Keywords:}

History of Photography; Postmodernism and Historical Story; Photo Historiography; Photography and Digital Culture. 


\section{Un momento ambivalente respecto al futuro de la propia Fotografía}

Estamos asistiendo a un tiempo en el que la Fotografía, como manifestación y práctica cultural, tiene una presencia cada vez más ambivalente entre nosotros. Es evidente que algunos de los iconos culturales creados en torno a ella en las últimas décadas han calado en la sociedad y diversas figuras del panteón fotográfico se han incorporado ya, en mayor o menor medida, al imaginario colectivo. En estos momentos no se ignoran algunos autores y creadores fotográficos gracias a que los medios de masas han amplificado y privilegiado a una serie de nombres y trabajos. Algunos autores de las vanguardias, como Man Ray, o reporteros como Robert Capa, por poner tan solo dos ejemplos muy evidentes, han sido expuestos hasta la saciedad y ya no son desconocidos ni tan siquiera por aquellas personas a las que no les interesa especialmente la cultura fotográfica. Las exposiciones que se exhiben de modo continuado atraen a un público, no necesariamente entendido, en muchos casos pertenecientes a las generaciones más jóvenes y aunque los efectos de la crisis se notan en el ámbito editorial con una cierta frecuencia siguen apareciendo monografías en torno a autores, pero al mismo tiempo apenas se publican entre nosotros libros de investigación o ensayos en torno al fenómeno cultural fotográfico y en muchas de las personas que formamos el colectivo dedicado al estudio de la fotografía en sus múltiples vertientes se ha instalado un cierto pesimismo, reforzado por la evidencia de que la fotografía digital ha convertido a la vista de todos nosotros a la tradición fotoquímica en poco menos que arqueológica en apenas una década, algo que agudamente autores como Martín Lister predijeron ya a mediados de la década de los años noventa, cuando la frontera entre las imágenes de base fotoquímica y las de estructura binaria comenzaban a convivir y se pensaba por muchos que el relevo tecnológico iba a producirse más lentamente de lo que en realidad ha sucedido: 
"Pensamos que estamos en el medio, quizá solo en los primeros momentos de esta transformación. -Escribía Martín Lister en 1995-. El drama de los cambios ocurridos se vincula a los grandes ciclos en la cultura visual occidental, desde los esquemas y símbolos de la imaginería medieval, al realismo en perspectiva del renacimiento y de la autografía a la fotografía en el siglo XIX. Como todos los cambios históricos, es mucho más que un cambio tecnológico en la que las imágenes están hechas para ser un juego. Dentro de este discurso en el que lo que se propone nada menos es un cambio de época. Cambio de como la naturaleza del mundo es ahora imaginada y captada. (De todos modos problemáticamente) para convertirse en un cambio de como el mundo es visto. Esos cambios ideológicos están en relación como ahora el mundo es conocido. (...) Y las identidades de quien ve y conoce en este momento. Más allá de estas referencias que están hechas en los corrientes de la economía, la política, y la producción, y los arreglos de las sociedades y comunidades en las que nosotros vivimos y adquirimos aquellas identidades" (Lister, M. 1995, p. 4)

\section{Algunos indicios del cambio en la percepción de la propia esencia del sujeto fotográfico en torno a una percepción pesimista.}

Apenas cinco años antes de que se publicara este trabajo seminal de Martin Lister sobre la imagen fotográfica digital, Fred Ritchin, en los Estados Unidos, ante los nuevos usos que comenzaban a producirse en las prácticas editoriales de edición fotográfica, se había interrogado sobre la revolución fotográfica que se esperaba, y lo hacía con la publicación de varios ensayos que incidían en los cambios que todavía apenas se vislumbraban, pero ya en aquellos tempranos momentos, Ritchin ponía el énfasis en uno de los elementos que iban a alterar toda la relación de la fotografía con la verdad captada a través del mundo de la información. Se iba a producir un intenso cambio en la percepción de la veracidad de las imágenes por parte de un público que, en términos generales, no estaba avisado sobre estos debates que si estaban ya surgiendo en los ámbitos académicos y profesionales más 
desarrollados. Las razones por los que la industria de la información comenzaba a usar estas tecnologías eran, ante todo, razones económicas basadas en los costes del producto informativo. Ritchin ponía algunos ejemplos de costo de producción en ilustraciones para los magazines ilustrados de los diarios que habían aconsejado usar el montaje digital para abaratar costes, y alertaba de algunos peligros que podían producirse en un campo mucho más delicado al que la fotografía había servido históricamente sin grandes fricciones dentro del campo de la memoria:

"No solo el periodismo, también las instantáneas de aficionados y la fotografía documental serán en corto tiempo afectadas. La historia cultural, los acontecimientos políticos, las memorias personales, todo quedará bajo sospecha cuando el largo reinado de la fotografía como alta tecnología de la sociedad pero humilde escriba de ella, se convierta en vulnerable. La fotografía de arte ya no sacará gran parte de su fuerza y contexto de una percepción que le es tan inherente como visible, realidades verificables, que serán más fáciles de ver como la pintura (...) Que se convertirán en un acto de la imaginación del artista. Con esta tecnología, la fotografía puede ser nuevamente orquestada (..) El mundo, más que hablar el dialecto de la fotografía convencional, se impondrá a sí mismo una imagen que estará siendo interpretada simultáneamente y que se convertirá en más controlable y que será más capaz de proyectar y confirmar sobre nosotros mismos y sobre nuestro propio mundo o cualquier otro, estas imágenes” (Ritchin, 1990, p. 5).

A lo largo de la década de los años noventa se fueron fraguando los elementos básicos de esa percepción pesimista en torno a la Fotografía que históricamente se había practicado y había acumulado un ingente conocimiento en torno a sus características específicas en la representación de la realidad y en la que la Historia y las Ciencias Sociales habían ido explorando y descubriendo diversos significados culturales y comunicativos. Ahora todo estaba comenzando a ser puesto de nuevo en revisión y los aspectos del debate quedaron claros desde que la imagen digital comenzó a ser una tecnología en expansión y sus nuevas funciones y formas de captación y visualización, afectaron a la propia esencia de la Fotografía. La 
veracidad fotográfica, o el inconsciente óptico, por usar un término de las vanguardias, comenzó a dar paso a unas imágenes con aspecto de fotografías pero que ya estaban más cerca del taller del pintor, por medio de los programas de retoque digital que del laboratorio químico del fotógrafo. William Mitchell en 1992, Nicholas Mirzoeff en 1999 (en un texto publicado en español en 2003), Fred Ritchin en 1990, o Martín Lister en 1995 por citar los autores que de modo más relevante abordaron en similares términos, a veces crudamente explícitos y a veces sugeridos, la pretendida muerte de la fotografía y sobre todo introdujeron un nuevo concepto cultural que ahora ya está plenamente vigente y es el de la postfotografía: "La postfotografía es la fotografía de la era electrónica que ya no intenta reflejar el mundo sino que se encierra en sí misma para explorar las posibilidades de un medio liberado de la responsabilidad de señalar la realidad" (Mirzoeff, 2003, p. 122).

Esa visión pesimista sobre el futuro de la fotografía como medio y testigo notarial de la realidad está ya fijada en el discurso de muchos críticos actuales y no se puede obviar que está en relación directa con el entusiasmo tecnocrático de la propia industria electrónica y digital, que ha crecido en un medio diferente al que hizo posible la imagen de base fotoquímica y que desconoce las tradiciones técnicas y las necesidades de los expertos que si obtenían respuestas en la investigación fotoquímica, algunas tan relevantes como la perdurabilidad de los registros fotográficos. Una respuesta que todavía resulta inconcreta en el ámbito digital y que, por el momento, obliga a una incesante migración para asegurar la pervivencia de las nuevas imágenes de base numérica. Cuestiones éstas muy relevantes porque la industria digital está orientada al consumo masivo y no a los requerimientos profesionales más específicos, como muy bien nos recordaba Franziska Frey en una conferencia que impartió en las Jornadas Antoní Varés de Girona en 2008 (Frey, 2008). De nuevo Fred Ritchin en su libro "After Photography" publicado en 2009 y en el que estudia las nuevas prácticas fotográficas que se han instaurado ya con los teléfonos móviles y otros dispositivos, retoma de nuevo esa persistente y evidente idea del cambio de naturaleza de lo 
fotográfico como un nuevo camino que ya no tiene relación con su pasada tradición y apunta ya a una conceptualización divergente entre ambos tipos de producciones basadas todavía en la captación de escenas a través de una cámara fotográfica: "Desde el siglo XIX la fotografía ha sido un medio de autoexpresión y un ambiguo constructo social, una estrategia para iluminar y certificar y al mismo tiempo para distorsionar y calcificar. Pero el medio ya no será lo que fue” (Ritchin, 2009, p. 185).

Para éste autor, como para otros tantos que siguen esta línea interpretativa, ha emergido una nueva tipología de imágenes a los que ya no se denomina ni tan siquiera fotográficas y que no parecen tener relación con las que han sido tradicionales antes del advenimiento y la socialización de la digitalidad, ni en su factura, ni en sus estrategias de relación con el espectador o con los canales clásicos de difusión:

"Finalmente, las fotografías digitales, en relación al espacio, al tiempo, a la iluminación, a la autoría, al resto de los media, dejan claro que representan un enfoque esencialmente diferente al que hace la fotografía analógica. También se pondrá de manifiesto que, en gran medida este grupo emergente de estrategias será para siempre vinculado con otras, como un componente más en el juego interactivo, interoperando en la red dentro de un más extenso metamedio. A este paradigma, que aún no ha emergido totalmente, se le puede llamar "hiperfotografía" (Ritchin, 2009, p. 141).

\subsection{El papel desconstructor de los relatos posmodernos y su conexión con la visión pesimista del futuro de la Fotografía.}

Pero la delimitación de dos etapas de las imágenes fotográficas en torno a sus características tecnológicas, ha venido acompañada de una evidente deconstrucción en torno a las propias concepciones culturales que han sustentado sus significaciones al menos en la historiografía elaborada desde el siglo XX y que en otros trabajos he intentado relacionar desde su transcurso histórico que hizo posible que los presupuestos historiográficos de los autores del siglo XIX centrados en la técnica dieran paso en el siglo XX a 
los estudios centrados en las imágenes y sus formas de presentar la realidad. Sin olvidarnos de Allan Sekulla, y otros autores que Jorge Ribalta recopiló en su influyente libro Efecto Real, es evidente que uno de los primeros trabajos elaborados con rigor y que abordaban ésta desconstrucción de las prácticas de exégesis tradicionales en torno a la historia de la fotografía fue el de Geoffrey Batchen, que ya en 1997, coincidiendo su obra con esta tendencia tecnológica a asistir al duelo de la fotografía tradicional, hizo una de las primeras incursiones muy argumentadas sobre ésta puesta en cuestión que había permanecido sin apenas discusión a lo largo de las décadas anteriores. En su libro Arder en deseos. La concepción de la fotografía que apareció en español en 2004, el propio objeto histórico era en su análisis, cuando menos dudoso o estaba insuficientemente enfocado:

“Tradicionalmente los críticos de fotografía han reformulado rápidamente ésta cuestión ontológica al abordarla como una cuestión histórica, es decir, como una búsqueda de los orígenes. La pregunta acerca de “¿qué es la fotografía?” se transforma fácilmente en ¿’donde y cuando comenzó la fotografía?” Las respuestas a esta segunda pregunta han sido fáciles de formular, ya que se apoyan en conceptos de historia que rara vez se analizan detenidamente y en pruebas que se consideran evidentes en sí mismas. Así pues, la historiografía de la fotografía está compuesta, en general, por un rápido movimiento desde las dificultades de la investigación filosófica a una simple y selectiva exposición de hechos. De éste modo, un edificio teóricamente frágil, el de la identidad señalada por la palabra "fotografía" se han levantado sobre unos cimientos pocas veces cuestionados, de información histórica incesantemente repetida" (Batchen, 1997, p. 29).

No es objeto de éste artículo debatir estos elementos que en el trabajo de Batchen están muy bien engarzados cuando analiza a autores centrales de la configuración de la historiografía fotográfica anterior a su libro. Es cierto que el giro interpretativo reside en que a Batchen, como a Sekulla y a tantos otros autores posmodernos hay que interpretarlos dentro de su propia escuela y en sus concepciones epistemológicas concretas en las que la historia no es más que un tipo de relato como lo son otros tipos de narrativa pero al que niegan 
toda cientificidad. Además, como muy bien sabemos los que transitamos entre la historia y las ciencias sociales con frecuencia, un término homónimo no significa necesariamente lo mismo en un enfoque metodológico o en otro. Precisamente por eso, es importante saber qué leemos cuando interpretamos los presupuestos conceptuales de cada autor concreto, y más en el ámbito cultural de la fotografía, cuyas aportaciones se han ido conformando a lo largo del tiempo desde diferentes campos de conocimiento.

No hay duda que estamos ante un complejo panorama de cambios de paradigmas que están implantándose en sustitución de los anteriores que tuvieron tan largo recorrido; de recepción de corrientes que están imponiéndose aun de modo fragmentado para un medio que, como le ha ocurrido a la Fotografía en el pasado, ha sido muy influyente socialmente pero que apenas ha ocupado un interés mayoritario en las humanidades y en las ciencias sociales y que se ha entendido al mismo tiempo como comunicativo, social o artístico, y por ese motivo se ha abordado en el siglo $\mathrm{XX}$ desde disciplinas y presupuestos tan diferentes y en ocasiones con interpretaciones divergentes. Este territorio, diverso epistemológicamente, a veces confuso por las diferentes procedencias intelectuales de quienes producen significados y contenidos en torno a las imágenes, la sociedad y el propio medio, es el territorio sobre el que hoy transitamos quienes nos dedicamos a explicar el significado histórico y cultural de la Fotografía. En eso consiste una parte de su atractivo, en la diversidad intelectual que tiene y en el entusiasmo que provoca. El problema estriba no tanto en pedir que las cosas sean más fáciles, sino en que sepamos navegar por su complejidad. Siempre recuerdo en este punto, aquel grito del poeta Baudelaire a mediados del siglo XIX cuando su realidad había cambiado y lo expresaba con aquel rotundo: iOdio mí tiempo! Porque le faltaba acabar la reflexión con una humilde realidad ilo odio, porque no lo entiendo! Y en eso reside el reto, en entender el tiempo interpretativo en el que nos encontramos. Una tarea que desde luego no es nada sencilla. 
3.- ¿La fotografía está "muerta" o ante una nueva encrucijada? Algunas apariencias y certezas.

Acabo de salir de una experiencia docente en la que he trabajado con alumnos en fase de formación doctoral que no estaban relacionados con el documento fotográfico, y que, finalmente, han terminado convencidos de que las imágenes sirven y mucho para explicar un tiempo concreto, pero que lo hacen de un modo diferente a los documentos escritos tradicionales, con una potencialidad que no presenta el propio documento escrito o impreso, a pesar de que la inmediatez de lo que muestran las imágenes necesita siempre de todo un aparato contextual y unos instrumentos de interpretación que son radicalmente diferentes a los de la escritura textual, pero para los que contamos ya con una relevante literatura científica en torno a la interpretación de las imágenes fruto de las aportaciones de muchos autores a lo largo de las últimas décadas. En mi opinión, la Fotografía como medio tecnológico no está muerto, sino en una nueva encrucijada, una más de las que tuvo que enfrentarse desde su invención en 1839, cuando empezó siendo un registro sobre metal, pasó al cristal y al papel, y en todos los momentos demostró su capacidad adaptativa a los cambios sociales, económicos, políticos y narrativos de un tiempo que se fue haciendo cada vez más y más complejo. La fotografía digital no hace sino adaptarse a una sociedad posmoderna, donde los límites precisos del pasado se han tornado difusos. Hoy lo objetivo y lo subjetivo están en el mismo plano, la ficción parece realidad y al contrario. ¿Por qué razón en esa sociedad de pensamiento débil tendría que resistir el valor de la veracidad fotográfica, cuando la idea de Objetividad está en derribo, cómo lo está la propia utopía del Progreso que ha sido tan persistente y ha atravesado el pensamiento de los autores de los siglos XIX y gran parte del siglo XX? El reto está en qué a quienes nos toca explicar la cultura creada con la Fotografía y en sus múltiples relaciones con la sociedad, nos toca también adaptar nuestro relato a la propia complejidad cultural en la que nos encontramos, que ya no puede reducirse a un positivismo objetivista de datos y descripciones, sino a una interpretación 
que se atreva a abordar la propia transversalidad social y cultural que ha tenido en su propio devenir histórico, sin que eso signifique en modo alguno que haya que alterar las condiciones históricas que identifican a cada etapa del pasado que tenía sus propios valores y en ellos residía el marco donde entendían e interpretaban las imágenes fotográficas los espectadores de su tiempo.

A pesar de la diversidad de las aproximaciones intelectuales, de lo minoritario que pueda resultar la especialidad en torno a la Fotografía y de las dificultades derivadas de la convivencia de diferentes epistemologías en torno a la interpretación de los documentos fotográficos, sigo siendo optimista respecto al recorrido del trabajo cultural sobre las significaciones de los fenómenos fotográficos y el enorme futuro que tiene trabajar en un campo que se relaciona con una de las formas de mostrar el mundo más relacionados con la densa iconosfera que nos envuelve. Vivimos rodeados de imágenes, en gran medida -aunque no todas, evidentemente-, de base y apariencia fotográfica, y su comprensión y análisis desde las que proceden del pasado hasta las que se producen en la actualidad es un campo de trabajo estimulante y atractivo. Nadar en sus memorias de fotógrafo del siglo XIX, escribió que la Fotografía le había dado mucho, y es cierto que es un medio generoso con quienes están en su derredor, la sensación de satisfacción descubriendo sus significados y compartiéndolos con otros interesados, es algo en lo que coincidimos todos los que nos dedicamos a entender éstas imágenes que no tienen precedentes históricos antes del siglo XIX y que ahora, como las interpretaciones en torno a ellas, están en una nueva mutación tecnológica y cultural que, al mismo tiempo, nos están revelando transformaciones sociales que se están produciendo y a las que una nueva forma de hacer imágenes fotográficas está intentando dar respuesta desde las practicas múltiples y con propósitos diversos que engloban las actividades fotográficas. 


\section{Por una historiografía que explique $y$ contemple interpretaciones conectadas con un tiempo hipervisual.}

En la presentación de La Cámara de Pandora, Joan Foncuberta apunta una idea que comparto y que me resulta de un enorme interés para el propósito de éstas reflexiones cuando escribe que:

"Cada sociedad necesita una imagen a su semejanza [y] la fotografía argéntica aporta la imagen de la sociedad industrial y funciona con los mismos protocolos (...) En cambio, la fotografía digital, es consecuencia de una economía que privilegia la información como mercancía” (Foncuberta, 2010, p. 12).

Es cierto que unos y otros llevamos muchos años a vueltas con los relatos historiográficos construidos en torno a la Fotografía. En 1994, Carmelo Vega y quien escribe este texto, intentamos indagar en los orígenes historiográficos en los que se sustentaba la fotografía, Carmelo desde la perspectiva de historiador del arte y yo desde mi base formativa de historiador contemporanista y ambos interesados también en aquellos años por la práctica fotográfica (Riego \& Vega, 1994). Un tema, el de la historiografía, que en mi caso abordé por última vez en 2003, en un libro titulado Fotografía. Crisis de Historia que editó, precisamente, Joan Foncuberta y en la que diversos autores exponíamos posiciones diferenciadas ante el fenómeno de la historia de la fotografía que estaba ya mutando y se sentía la necesidad de superar modelos historiográficos que si bien habían cumplido el objetivo de poner en valor cultural a la Fotografía, se habían agotado en sus planteamientos. Fotografía. Crisis de Historia es sin duda en nuestra bibliografía, el eslabón entre los modos de hacer historia que practicamos con mayor o menor fortuna desde la década de los años ochenta, y la cada vez mayor primacía que están adquiriendo los relatos posmodernos en torno a la Fotografía, una visión que entre nosotros introdujo, como ya he mencionado anteriormente, Jorge Ribalta con su libro Efecto Real y la exposición que comisarió en el MACBA sobre la utopía de la documentalidad, en el año 2008, bajo el título de Archivo Universal. 
Pocas generaciones tienen el privilegio de haber sido parte activa de la puesta en marcha de un modelo historiográfico, debatir, asistir y participar en sus evoluciones y transformaciones metodológicas que han dado como resultado una extensa producción de textos y materiales y décadas después encontrarse con que el propio objeto de estudio ha sufrido en el camino una mutación tan grande que algunos autores dudan ya hasta de su propia utilidad para el presente y de interés para el devenir en un tiempo que cada vez es más hiper audiovisual. Una época en la que, solo en 2013, se colocaban en Youtube siete horas de video en cada minuto transcurrido. Un tiempo que asiste a una avalancha de información por múltiples canales y pantallas y en los que una imagen fija y estática extraída de la realidad parece ya algo muy pequeño en relación con los excesos visuales y audiovisuales a los que asistimos cada día. Pero al mismo tiempo no podemos olvidar que la sociedad en la que vivimos inundados de imágenes y estímulos visuales solo ha sido posible por su herencia fotográfica y por la densidad icónica que desde el siglo XIX fue adquiriéndose, que se multiplicó después por el fotograbado y en estos momentos por el desarrollo, aún no concluido, tecnologías digitales.

\section{La desconexión entre la práctica fotográfica y el conocimiento teórico en la construcción historiográfica más reciente.}

En un esquema clásico, quienes nos hemos dedicado a indagar sobre el fenómeno fotográfico en su relación con la historia, contábamos con el siglo XIX como etapa de nacimiento y primera identidad social de la tecnología, del medio, o del proceso expresivo, dependiendo la perspectiva de aproximación historiográfica que se hiciese en torno a la Fotografía, más tarde, el siglo XX como la etapa de maduración dentro de la sociedad de las masas en las formas narrativas, a las que se denominaron "nueva visión", "fotografía de la modernidad" u otras etiquetas en las que fuimos descubriendo y consumiendo autores que han pasado ya al imaginario colectivo, y a finales del siglo XX fue emergiendo un fenómeno diferente; la denominada imagen (que no fotografía) digital, que planteaba nuevos 
paradigmas de análisis y que en apenas una década logró que se fuera desvaneciendo de manera inexorable toda la tradición fotoquímica tan sólidamente arraigada y que tenía un contexto industrial de investigación que en pocos años se ha ido quedando obsoleto. Cuando hace años estudiábamos un autor, una época del desarrollo fotográfico o una técnica que había conseguido logros expresivos, nos movíamos en una tradición tecnológica que con variaciones formales seguía siendo la misma, y de la que quienes trabajábamos en éste campo entendíamos perfectamente. Pero esta continuidad no está ahora asegurada ya que los nuevos investigadores que se interesan por el fenómeno fotográfico, y los que vengan en las próximas décadas, habrán perdido ya la conexión con la tradición tecnológica y fotoquímica de la fotografía y tendrán que hacer verdaderas incursiones arqueológicas para poder entender elementos de su estudio que sean pertinentes con el análisis que están desarrollando. Hace muy poco tuve esa primera percepción cuando en una tesis doctoral, la autora, que estaba defendiendo un magnífico trabajo, se sintió obligada a dedicar unas páginas a explicar cómo era y cómo captaba las fotografías una cámara tipo Rolleiflex de doble objetivo. Mi primera reacción fue de sorpresa por lo innecesario que me parecía esa explicación, pero pronto entendí que hay investigadores actuales que no han tenido contacto con esas realidades de la tecnología fotográfica y su aproximación ya no parte de la experiencia sino del conocimiento teórico. Porque es evidente que muchos de los que hemos construido historia de la fotografía en estos años lo hemos hecho también con un conocimiento y una práctica técnica que nos permitía dar por supuestas algunas cuestiones básicas, que en el futuro habrá que explicar o, cuando menos, reconstruir. Del mismo modo que ahora cuando explicamos un espectáculo visual como el mundonuevo, tenemos que imaginarnos la experiencia porque como autores nunca tuvimos prácticas directas respecto a sus formas y modos narrativos.

Lo que le ha ocurrido a la fotografía, también le ha sucedido a otras tecnologías de muy extensa influencia social y que ahora han mutado de un 
modo tan radical que también su arqueología resulta problemática. Es el caso de la imprenta, cuyos procesos actuales son radicalmente diferentes a los que se practicaban hace tan solo unas décadas, sumidos en procesos industriales en los que los tipos de metal y una serie de especialidades en torno al texto, se han convertido ya en una memoria difusa, porque cada vez quedan menos supervivientes de aquellas técnicas profesionales. Es ley de vida, se dirá, pero sobre todo es la inexorable implosión de la digitalidad que ha cambiado la relación histórica con los procesos y las materias que constituían nuestra tradición cultural, algo que también ha sucedido en torno a la propia construcción de las imágenes. Hasta ahora nos resultaba fácil e incluso era evidente entender que la proyección de una imagen fotográfica en función de la distancia focal de la cámara que la había captado, era heredera de las reglas de la perspectiva renacentista, y eso explicaba que autores como David Hockney reivindicaran un "conocimiento secreto" en la pintura y “descubriera” que muchos pintores se valieron de cámaras oscuras para poder detallar con mucho realismo las figuras de sus cuadros. La continuidad entre las reglas pictóricas y las proyecciones fotográficas de la cámara oscura han sido bien estudiadas desde el trabajo que Peter Galassi publicó en 1984 bajo el título de Before Photography, sin embargo, ahora nos encontramos que las imágenes salidas de los dispositivos selfmedia, tal y como los ha etiquetado Patrice Flichy en su libro sobre el imaginario de Internet, en esos nuevos dispositivos, por ejemplo la cámara de un teléfono móvil; no tienen ni tan siquiera, por su mínimo grosor, la distancia focal requerida para que las proyecciones fotográficas parezcan iguales a las que hacían anteriormente las cámaras de base fotoquímica, y tiene que ser un software interno el que se invente y literalmente reconstruya éste principio básico de proyección en perspectiva que permita a las imágenes de base digital captadas por estos aparatos parecerse a las que históricamente hemos aceptado como realistas, a pesar de que gracias a la interpretación que hace el software que procesa la imagen captada, las proyecciones en perspectiva de las imágenes digitales, son tan solo una de las muchas posibilidades que se podían configurar en la apariencia final, sin olvidarnos que los nuevos dispositivos de captación de 
imágenes portan también capacidades de difusión y almacenamiento que nada tienen que ver con las prácticas culturales del pasado en torno a la captación de las imágenes fotográficas que necesitaban de un paso por el laboratorio o de un proceso químico producido in situ como ocurría con las Polaroid. Nadie nos asegura que en el futuro esas premisas heredadas en los dispositivos digitales elaboren otro tipo de imágenes que ya no hereden las propiedades visuales de la Fotografía de base argéntica que a su vez son consecuencia de la cultura de la representación pictórica renacentista.

¿En dónde estamos en un momento como el presente? Evidentemente ante un tiempo nuevo en el que algunos de los métodos que nos han servido en el pasado tienen que ser reconfigurados. Me parece muy útil que desde diferentes ámbitos de conocimiento se explique el fenómeno cultural, social, estético o comunicativo de la Fotografía y que se tiendan puentes en esa diversidad epistemológica, que aunque parece complicar las cosas, en mi opinión, enriquece las perspectivas de análisis. Ese encuentro era uno de los objetivos de éste monográfico. En el caso de la historiografía es notorio que hay que dar un nuevo paso, en mi opinión en la dirección de insertar el estudio de la Fotografía y sus imágenes en un contexto cultural más integrado. Si en la década de los años ochenta nuestro objetivo era hacer notar el valor de lo fotográfico que era ignorado en la construcción cultural de entonces, en estos momentos sin duda la utilidad de la historia de la fotografía, consistirá sobre todo en insertar los fenómenos fotográficos, cualesquiera que hayan sido, en un contexto más integrado que explique mejor las influencias, las relaciones y la propia transversalidad de las imágenes fotográficas en un discurso que tiene que ser mucho más afinado. Tal vez hemos usado y abusado mucho de la práctica de "extraer" un fenómeno cultural de su contexto para estudiarle mejor y hacerlo de modo aislado porque era más cómoda su explicación, y ahora el reto esté justamente en integrar el fenómeno estudiado en un complejo mucho más extenso, que nos permita comprender aspectos que se nos han pasado por alto. La intertextualidad cultural de las imágenes fotográficas, es evidente, 
pero nos hemos dedicado poco a explorar en esa dirección y es sin duda una de las líneas de indagación en los años venideros.

Es posible que el estudio de la Fotografía siga siendo una actividad minoritaria y es deseable que aparezcan en las generaciones más jóvenes nuevos expertos que en muchos casos remodelarán los presupuestos metodológicos que hemos aplicado en el pasado. Pero no hay lugar para el pesimismo, hemos conseguido con el trabajo de muchos que la Fotografía sea ya una parte de las manifestaciones culturales reconocidas desde los autores del siglo XIX, quedan muchas cuestiones por estudiar, hay muchos aspectos que aun conocemos mal, necesitamos nuevas formas de aproximación conceptual que irán apareciendo y inventar estrategias de difundir lo estudiado con los nuevos soportes que la propia digitalidad está creando, nuevas formas y métodos que tendrán que adaptarse a un tiempo que ya es diferente, una nueva encrucijada en la que de nuevo y como dijo François Arago cuando presentó el daguerrotipo en la Academia de Ciencias de París en enero de 1839: "ante todo tenemos que permanecer atentos a lo imprevisto".

\section{Referencias bibliográficas}

Batchen G. (2004) (original en 1997). Arder en Deseos. La concepción de la Fotografía. Barcelona: Gustavo Gili.

Foncuberta, J. (2010). La Cámara de Pandora. La Fotografi@ después de la Fotografia” Barcelona: Gustavo Gili.

Foncuberta, J. (Editor) (2003). Fotografía. Crisis de Historia. Barcelona: Actar.

Frey, F. (2008). Creació de Collec.cions Digitales. Girona: Actas de las Jornadas Antoni Varés. Documento en línea: http://www.girona.cat/sgdap/docs/nmr36udfranziska\%2ofrey.pdf

Galassi, P. (1984). Before Photography. Painting and The Invention of Photography. New York: MOMA.

Hockney, D. (2001). El conocimiento secreto. Madrid: Destino.

Lister, M. (1995). The photographic image in digital culture. London: Routledge. 
Mitchell, W. J. (1992). The Reconfigured Eye. Visual Truth in the PostPhotographic Era. Masachussets: MIT Press.

Mirzoeff, N. (2003) (original en 1999). Una introducción a la Cultura Visual. Madrid: Paidós.

Ribalta, J. (Editor) (2004). Efecto Real. Debates posmodernos sobre fotografía”. Barcelona: Gustavo Gili.

Ribalta, J. (2008). “Archivo Universal” Barcelona: MACBA.

Riego, B. y Vega, C. (1994). Fotografía y métodos históricos, dos textos para un debate. Santander: Universidad de Cantabria, Universidad de la Laguna.

Ritchin, F. (2009). After Photography. New York: W.W. Norton.

Ritchin F. (1990). In Our Own Image. The Coming Revolution in Photography”. New York: Aperture.

Cómo citar: Riego, B. (2015). "La Historia de la fotografía ante un nuevo tiempo cultural: reflexiones para un encuentro interdisciplinar". Fotocinema. Revista científica de cine $y$ fotografía, 10, pp. 9-25. Disponible: http://www.revistafotocinema.com/index.php?journal=fotocinema\&page $=$ ar ticle\&op =view\&path[]=273 